Original clinical investigation

Open Access

\title{
Examining warfarin underutilization rates in patients with atrial fibrillation: Detailed chart review essential to capture contraindications to warfarin therapy
}

\author{
Ajay Srivastava1, Michael Hudson², Ihab Hamoud ${ }^{1}$, Joao Cavalcante ${ }^{1}$, \\ Chetan Pai ${ }^{1}$ and Scott Kaatz*1
}

Address: ${ }^{1}$ Department of Internal Medicine, Henry Ford Hospital, Detroit, MI, USA and ${ }^{2}$ Heart and Vascular Institute, Henry Ford Hospital, Detroit, MI, USA

Email: Ajay Srivastava - asrivas1@hfhs.org; Michael Hudson - mhudson1@hfhs.org; Ihab Hamoud - ihammou1@hfhs.org;

Joao Cavalcante - jcavalc1@hfhs.org; Chetan Pai - cpai1@hfhs.org; Scott Kaatz* - skaatz1@hfhs.org

* Corresponding author

Published: 3 June 2008

Thrombosis Journal 2008, 6:6 doi:10.1 186/1477-9560-6-6

This article is available from: http://www.thrombosisjournal.com/content/6/1/6

(C) 2008 Srivastava et al; licensee BioMed Central Ltd.

This is an Open Access article distributed under the terms of the Creative Commons Attribution License (http://creativecommons.org/licenses/by/2.0), which permits unrestricted use, distribution, and reproduction in any medium, provided the original work is properly cited.

\begin{abstract}
Introduction: Atrial fibrillation affects an estimated 2.5 million Americans and incurs an average annual stroke risk of $4.5 \%$ per year. Despite warfarin reducing stroke risk by approximately $66 \%$, prior studies show warfarin usage rates to be about $50 \%$. However, the methods that define warfarin as "inappropriate underutilization" might not be sensitive enough to pick up relative contraindications. We assessed the inappropriate underutilization of warfarin in atrial fibrillation patients at our hospital by abstracting individual patient charts.
\end{abstract}

Methods: Medical records were reviewed to determine stroke risk factors, warfarin use, and documented contraindications to warfarin use in 364 consecutive patients with atrial fibrillation.

Results: Amongst 364 atrial fibrillation patients, 54.6\% received warfarin anticoagulation. Overall, $29.5 \%$ of patients had documented reasons for not prescribing warfarin. Primary reasons listed by treating physicians included: gastrointestinal bleed $10.7 \%$, secondary/transient atrial fibrillation $8.2 \%$, and fall risk $6.3 \%$. Only $7.1 \%$ of the patients had no documented reasons for the lack of warfarin use.

Conclusion: Consistent with previous reports, $45.4 \%$ of patients in this atrial fibrillation cohort were not prescribed warfarin. However, after reviewing medical charts for documented reasons why warfarin was not used, the inappropriate underutilization rate was only $7.1 \%$. These findings suggest that studies utilizing administrative database and ICD-9 CM coding might overestimate warfarin underutilization.

\section{Introduction}

Atrial fibrillation (AF) currently affects an estimated 2.5 million patients in the United States and this number is expected to double within the next 20 years. [1,2] AF is particularly prevalent in the elderly population affecting 1 in 10 people over the age of 80 and accounting for one quarter of all strokes in the elderly population. [1] Patients with AF not receiving antithrombotic therapy 
have a stroke risk of $4.5 \%$ per year. [3-5] While studies have shown that warfarin therapy could reduce this stoke risk by about $66 \%[6]$, it is distressing to note that warfarin therapy remains widely underutilized [7-9], with bleeding risk and monitoring concerns being cited as the most common reasons for nonuse.

Prior studies analyzing warfarin utilization in patients with AF have generally relied on administrative data in determining patient's candidacy for warfarin therapy. [712] Due to the inherent study design and methodology, warfarin underutilization rates can be overestimated in such studies by including patients with relative or perceived contraindications to anticoagulation. The objectives of this study were a) To determine the rate of warfarin underutilization in a cohort of AF patients by retrospectively reviewing medical charts including physician verification of electrocardiograms (EKG), b) To compare methodologies of prior studies investigating warfarin underutilization and the role of chart review in estimating warfarin underutilization in AF patients and c) Attempt to identify physician-professed reasoning for not initiating warfarin therapy and analyze the adequacy of these reasons/contraindications.

\section{Methods \\ Study Population}

We retrospectively reviewed medical records of 364 patients with atrial fibrillation, after EKG confirmation by a cardiologist, and at least 1 year of follow-up from the index EKG. Index EKGs were obtained from inpatient and outpatient data from January 1, 2002, through December 31,2003 . The study was approved by the Henry Ford Hospital Institutional Review Board.

\section{Variables}

Electronic medical records were reviewed for stroke risk factors, which included baseline demographic variables and previous diagnoses of stroke/transient ischemic attack (TIA), congestive heart failure (CHF), myocardial infarction (MI), coronary artery disease (CAD), hypertension, and diabetes mellitus (DM). Clinic notes and hospital discharge summaries were reviewed to identify physician documented reasons for not prescribing warfarin therapy. Patient race/ethnicity was obtained from demographic profiles listed in electronic medical records. Gastrointestinal bleed was considered to be a limiting factor if there was a physician note documenting prior history of bleeding or guaiac-positive stools. Non-gastrointestinal bleeds included bleeding from all other causes, such as hematoma and trauma. Fall risk was recorded if there was a physician note stating increased risk for falls or unfavorable fall risk to warfarin benefit ratio. Patients were considered to have transient or secondary AF if there were EKGs documenting AF during an acute event, such as sur- gery or acute medical illness with all subsequent EKGs showing normal sinus rhythm and physician notes stating warfarin was not indicated. Patients with a prior diagnosis of AF that had converted to sinus rhythm during followup were also included in this group. Patient compliance was considered a factor if there were physician notes stating that the patient had a previous history of non-compliance to medical therapy. Coagulopathy included patients with an underlying bleeding or coagulation disorder placing them at an increased risk for bleeding. $\mathrm{CHADS}_{2}$ (Ccardiac failure, $\mathrm{H}$-hypertension, A-age $>75$ years, D- diabetes mellitus, S- stroke) index is a point-based system to stratify stroke risk and thereby help guide with anti-coagulation decision-making in patients with AF.[3] 2 points are assigned for previous stroke or TIA and 1 point each for age $>75$ years, hypertension, diabetes mellitus or recent congestive heart failure. The total score calculated then helps determine the stroke risk, with higher the $\mathrm{CHADS}_{2}$ score greater the risk of stroke.

\section{Statistical Analysis}

A descriptive analysis was performed to compare baseline clinical and demographic characteristics between patient groups receiving warfarin and those not receiving warfarin. The chi-square test was used for categorical variables and Student's $t$ test for the continuous variables. The $\mathrm{CHADS}_{2}$ score between the two groups were compared using the Wilcoxon rank sum test. After breaking down the $\mathrm{CHADS}_{2}$ variable into its individual scores, a CochranArmitage trend test was performed to compare warfarin usage based on $\mathrm{CHADS}_{2}$ score, with a $p$ value of .05 suggesting a statistically significant difference. All statistical analyses were performed using SAS software (version 8.2).

\section{Comparing Prior Studies Investigating Warfarin Underutilization}

A systematic literature search using the MEDLINE computerized database was performed (January 1, 1995, to December 1, 2005). Relevant studies were identified by using the following keywords: "warfarin, underutilization, coumadin, fall risk, atrial fibrillation, $\mathrm{CHADS}_{2}$, anti-coagulation in atrial fibrillation, stroke risk, gastrointestinal bleed, transient atrial fibrillation, intracranial hemorrhage, elderly". Bibliographies of each article were reviewed to identify additional articles. Articles relevant to the present study were than tabulated into a table and warfarin utilization rates were compared based on study period, health care setting and study methodology.

\section{Results}

Of the 364 patients, 199 patients (54.6\%) received warfarin. Patients who received warfarin were younger than 75 years compared to patients who did not receive warfarin (table 1), and African American patients were less likely to receive warfarin. Only 5 patients $(1.3 \%)$ had a $\mathrm{CHADS}_{2}$ 
Table I: Characteristics of Patients with AF classified based on Warfarin Use

\begin{tabular}{|c|c|c|c|}
\hline Characteristics & Received Warfarin $\mathrm{n}=199$ & Did Not Receive Warfarin n = I65 & $p$ value \\
\hline Age, years, mean & $76.3 \pm 11.3$ & $81.3 \pm 10.3$ & $<0.00 I^{*}$ \\
\hline Age $75 \geq y, n(\%)$ & $125(62.8)$ & $134(81.2)$ & $<0.001 *$ \\
\hline AA Race, n (\%) & $74(37.2)$ & $82(49.7)$ & $0.016 *$ \\
\hline Women, n (\%) & $76(38.2)$ & $79(47.9)$ & 0.063 \\
\hline CAD, n (\%) & $92(46.2)$ & $87(52.7)$ & 0.217 \\
\hline Mean $\mathrm{CHADS}_{2}$ Score \pm S.D & $2.8 \pm 1.3$ & $3.2 \pm 1.3$ & $0.004 *$ \\
\hline CHADS $_{2}$ Score- 3 or greater (\%) & III (56) & $116(70)$ & $0.004 *$ \\
\hline \multicolumn{4}{|l|}{ Chads $_{2}$ Score } \\
\hline 0 & $3(1.5)$ & $2(1)$ & \\
\hline I & $22(\mathrm{II})$ & $12(7)$ & \\
\hline 2 & $63(32)$ & $35(21)$ & \\
\hline 3 & $59(30)$ & $58(35)$ & \\
\hline 4 & $32(16)$ & $28(17)$ & \\
\hline 5 & $15(7.5)$ & $22(14)$ & \\
\hline 6 & $5(2.5)$ & $8(5)$ & \\
\hline Heart Failure, n (\%) & $120(60.3)$ & $103(62.4)$ & 0.679 \\
\hline Diabetes, n (\%) & $68(34.2)$ & $66(40.0)$ & 0.251 \\
\hline Hypertension, n (\%) & $179(90.0)$ & $149(90.3)$ & 0.911 \\
\hline Prior Stroke, n (\%) & $47(23.6)$ & $43(26.1)$ & 0.591 \\
\hline
\end{tabular}

Abbreviations: AA- African American, CAD- Coronary Artery Disease, CHADS2- C-cardiac failure, H-hypertension, A-age > 75 years, D- diabetes mellitus, S- stroke, S.D- Standard deviation

*Statistically significant, $p<0.05$

score of zero and 34 patients $(9.3 \%)$ had a $\mathrm{CHADS}_{2}$ score of 1 , suggesting a moderate-to-high risk of thromboembolism in the study population. There were no significant differences in the proportion of patients with prior hypertension, stroke, cardiac disease, or diabetes between patients prescribed warfarin and those not receiving anticoagulation. As shown in Table 1, the mean overall $\mathrm{CHADS}_{2}$ score was higher in patients not receiving warfarin compared to patients on warfarin therapy $(3.2 \pm 1.3 \mathrm{vs}$. $2.8 \pm 1.3, p<.004)$. Also, there were more patients with a $\mathrm{CHADS}_{2}$ score of 3 or greater in the cohort not on warfarin therapy, compared to the group on warfarin therapy $(70 \%$ vs. $56 \%, p=0.004)$. A detailed review of medical records revealed documented reasons for not prescribing warfarin in $83 \%(137 / 165)$ of patients not receiving warfarin. Prior or recent gastrointestinal bleeding was the most often cited contraindication to warfarin therapy; with other perceived reasons listed in Table 2. Only 7.1\% (26/364)

Table 2: Physician's Perceived Reasons for Not Initiating Warfarin Therapy $(\mathbf{N}=137)$

\begin{tabular}{ll}
\hline I. History of Gastrointestinal Bleed & $-39(28 \%)$ \\
2. Transient/Secondary AF & $-30(22 \%)$ \\
3. Fall Risk & $-23(17 \%)$ \\
4. Patient preference & $-19(14 \%)$ \\
5. History of Non-Gastrointestinal Bleed & $-11(8 \%)$ \\
6. Poor Patient Compliance & $-8(6 \%)$ \\
7. Coagulopathy & $-5(4 \%)$ \\
8. Miscellaneous & $-2(1 \%)$
\end{tabular}

patients did not have a documented reason for warfarin non-use.

Table 3 compares the prior studies that have examined warfarin utilization in AF patients. Warfarin utilization rates very between $38 \%-s 61 \%$ in the larger population studies that employ ICD-9-CM (The International Classification of Diseases, Ninth Revision, Clinical Modification) diagnostic codes, administrative or billing databases for assessing warfarin use while the rates drop significantly lower in the smaller patient cohort studies that review medical charts and account for reasons for warfarin nonuse.

\section{Discussion}

The present study conducted at a single tertiary care center shows that $45 \%$ of AF patients did not receive antithrombotic therapy with warfarin. However, individual medical chart review revealed that $83 \%$ of patients not prescribed warfarin had a real or perceived documented reason for warfarin nonuse cited by the healthcare provider. After taking these factors into account, only $7.1 \%$ of ideal candidates for warfarin therapy were not receiving warfarin therapy.

McCormick et al [12] showed an overall warfarin utilization of $42 \%$ (180/429), but a further detailed chart review of 83 "ideal warfarin candidates" demonstrated 75\% warfarin use in those with no potential warfarin contraindica- 
Table 3: Comparison of Patient Selection Methods in Prior Studies Examining Warfarin Utilization in AF Patients

\begin{tabular}{|c|c|c|c|c|c|c|c|}
\hline Study Period & Author & Setting & $\begin{array}{l}\text { Patient } \\
\text { Selection for } \\
\text { AF based on }\end{array}$ & $\begin{array}{c}\text { Patient } \\
\text { Population } \\
\text { Size }\end{array}$ & $\begin{array}{c}\text { Warfarin } \\
\text { Utilization \% }\end{array}$ & $\begin{array}{c}\text { "Warfarin } \\
\text { Candidates" } \\
\text { not on } \\
\text { Warfarin \% }\end{array}$ & $\begin{array}{l}\text { Method of } \\
\text { determining } \\
\text { Warfarin } \\
\text { Utilization }\end{array}$ \\
\hline $1995-1998$ & $\begin{array}{l}\text { Weisbord et } \\
{\text { al. }{ }^{13}}^{\text {a }}\end{array}$ & VA & $\begin{array}{l}\text { Medical Chart } \\
\text { review }\end{array}$ & 1289 & 65 & 3.5 & $\begin{array}{l}\text { Medical Chart } \\
\text { reviewed by } \\
\text { physicians for } \\
\text { documented } \\
\text { contraindication }\end{array}$ \\
\hline $1996-1997$ & Go et al. ${ }^{.1}$ & Large HMO & ICD-9-CM code & 13428 & 55 & 37.9 & $\begin{array}{c}\text { Pharmacy } \\
\text { database, } \\
\text { Outpatient INR, } \\
\text { ICD for } \\
\text { "Coumadin } \\
\text { Therapy" }\end{array}$ \\
\hline 1997-1998 & $\begin{array}{l}\text { McCormick et } \\
\text { al. }{ }^{12}\end{array}$ & $\begin{array}{l}\text { Long term Care } \\
\text { Facility }\end{array}$ & $\begin{array}{l}\text { Medical Chart } \\
\text { reviewed for } \\
\text { EKG diagnosis or } \\
\text { documentation } \\
\text { by physician }\end{array}$ & 429 & 42 & 32 & $\begin{array}{l}\text { Warfarin } \\
\text { prescriptions, } \\
\text { INR, Physician } \\
\text { Notes }\end{array}$ \\
\hline 2000-2002 & Waldo et al. ${ }^{9}$ & $\begin{array}{l}\text { Teaching, } \\
\text { community and } \\
\text { VA hospitals }\end{array}$ & ICD-9-CM code & 945 & 54 & 22 & $\begin{array}{l}\text { ICD-9 \& Medical } \\
\text { chart review }\end{array}$ \\
\hline 2000-2005 & Darkow et al. ${ }^{7}$ & $\mathrm{HMO}$ & ICD-9-CM code & 12539 & 39 & 61 & Unable to obtain \\
\hline $200 I-2003$ & Hylek et al. ${ }^{8}$ & $\begin{array}{l}\text { Urban teaching } \\
\text { hospital }\end{array}$ & $\begin{array}{l}\text { Electronic } \\
\text { medical chart } \\
\text { review and ECG } \\
\text { verified } A F\end{array}$ & 405 & 51 & 2 & $\begin{array}{l}\text { Electronic } \\
\text { medical chart } \\
\text { review for } \\
\text { physician cited } \\
\text { reasons for } \\
\text { warfain non-use }\end{array}$ \\
\hline 2004-2005 & Our Study & $\begin{array}{l}\text { Single Tertiary } \\
\text { Care Hospital }\end{array}$ & $\begin{array}{l}\text { Medical Chart } \\
\text { review and } \\
\text { physician } \\
\text { confirmation of } \\
\text { AF by EKG }\end{array}$ & 364 & 54 & 7.1 & $\begin{array}{l}\text { Medical chart } \\
\text { reviewed by } \\
\text { physicians for } \\
\text { documented } \\
\text { contraindication }\end{array}$ \\
\hline
\end{tabular}

tions. Similarly, Weisbord et al [13] and Hylek et al [8] showed a dramatic decrease in warfarin underutilization rates after employing chart reviews and excluding patients with documented contraindications to warfarin therapy. Further, in a recent report Waldo et al [9] from the NABOR (National Anticoagulation Benchmark Outcomes Report) Committee studied warfarin underutilization in hospitalized patients with AF and showed initial warfarin underutilization rates of about $54.4 \%$, but in the high-risk stroke AF patients, after taking bleeding considerations into account, the underutilization was reduced by $10 \%$. Review of other prior studies examining AF underutilization (table 3) cumulatively suggest that published rates of warfarin underutilization are highly influenced by the rigor used to review patient charts, and that administrative database reviews can underestimate the proportion of patients with real or perceived relative contraindications to warfarin use.

As shown in table 1, a greater percentage of patients in the non warfarin group had a $\mathrm{CHADS}_{2}$ score of 3 or greater $(70 \%$ vs. $56 \%, p=0.004)$. This is of extreme concern as AF patients with high calculated stroke risk are not being treated with warfarin therapy due to one or more physician perceived contraindications. Primary documented reasons for warfarin non-use in our study included history of GI bleeds (39/165), transient/secondary AF (30/165), and fall risk (23/165).

History of GI bleed accounted for 29\% (39/137) of the warfarin candidates not on warfarin therapy in our study. Our finding is in agreement with prior studies, that physicians are less likely to initiate antithrombotic therapy in patients with a history of GI bleed.[14,15] This concern is understandable; considering persons on warfarin therapy are not only more likely to develop major GI tract bleeding (2-fold higher) but also, this risk also increases with age. $[16,17]$ Yet, Man-Son-Hing and Laupacis showed in their study [18] that in order not to benefit from warfarin therapy, the person must have a significantly high risk of upper GI tract bleeding (> 10.4\% per year) or a stroke risk less than $2.4 \%$ per year (patients with AF carry a $4.5 \%$ annual stroke risk). They further suggested a treatment model to help guide antithrombotic therapy in AF 
patients with a history of upper GI tract bleeding. As lower GI tract bleeding was not included in the model, Beyth suggested in the same study, that a treatment model to help guide physicians should attempt to include other factors known to augment the risk for both upper and lower GI bleed such as older age, non-steroidal anti-inflammatory drugs, $[19,20]$ steroid use, $[21]$ proton pump inhibitors, alcohol consumption, cigarette smoking and warfarin noncompliance. GI bleed can occur due to different reasons and in some cases can be related to a specific causative factor or event that led to the bleed. It is reasonable to think that removal of the causative factor or treatment should not place the patient at risk for future bleeding or make them ineligible for warfarin therapy, especially if the therapy is to occur years later. Future research should examine this specific cohort closely to help better identify potential patients who could otherwise benefit from warfarin therapy.

The second most common reason for not starting warfarin therapy was transient or secondary AF. It is clear from the current literature that this group of patients should be treated as AF patients and be given warfarin therapy.[9,22] To correct this oversight and diminish the number of such cases, healthcare providers must be made aware of warfarin therapies and educated in depth.

Fall risk was the third most commonly reported reason in our patient cohort for not prescribing warfarin, and as falls are associated with the elderly population [23-25] in which AF is highly prevalent, this is particularly a noteworthy finding. There is much ambiguity involved when a patient is labeled as "fall risk". [26] As shown in prior studies, patients are often not started on anti-coagulation for fear of the bleeding risk that is associated with falls.[27] We agree that this is a difficult topic to assess, as fall or neurological illness histories not routinely investigated or taken into account, but such histories are highly variable and subjective, based on the healthcare provider and the patient. Despite all these issues, we believe this is a key area for clinical improvement. Previous studies have cited fall risk and intracranial hemorrhage as the major reasons for not initiating anticoagulation in AF patients, especially the elderly.[23,27,28] The recent Birmingham Atrial Fibrillation Treatment of the Aged (BAFTA) trial [25] showed that even in an older AF patient group, warfarin decreased fatal stroke $(1.8 \%$ per yr vs. $3.8 \%$ per year), and did not increase intracranial hemorrhage risk (1.4\% per year vs. $1.6 \%$ per year) compared to aspirin therapy. Moreover, Gage et al [24] demonstrated that while older patients are at high risk for falls and carry an increased risk for intracranial hemorrhage, these patients also have a higher stroke risk, and therefore would likely benefit from anticoagulant therapy. These studies emphasize the point that fear of intracranial hemorrhage might be overestimated in this patient cohort. Indeed, a recent study by Jacobs [29] showed that effective management of warfarin can be achieved in the elderly by careful attention to these issues. Healthcare institutions should also consider employing objective methods to identify patients at fall risk by utilizing screening forms and taking patient, physician, and social factors into consideration.

This study has limitations inherent to a retrospective chart review. Our study was confined to a single center, and practice patterns might vary at other hospitals. Data collection regarding warfarin contraindications was limited to the available medical record content and no pre-specified or verifiable criteria were applied to the physiciancited contraindications for nonprescription of warfarin. The limited sample size in the group with documented perceived contraindications prevented further analysis to examine the adequacy of the contraindication to warfarin therapy.

In conclusion, our study found documented reasons for warfarin nonuse in a majority of the patients, as after a detailed medical chart review, only $7.1 \%$ of ideal candidates for warfarin therapy were not receiving it. These findings suggest that administrative database studies might overestimate warfarin underutilization in $\mathrm{AF}$ patients and that physician omission/error is not the primary cause of warfarin underutilization. There is an urgent need for prospective studies to investigate relative warfarin efficacy and bleeding risks in patients with perceived warfarin contraindications, as it would help guide healthcare providers in warfarin prescribing and consequently reduce the risk of AF-related disabling strokes.

\section{Abbreviations}

AF: atrial fibrillation; ICD- CM: The International Classification of Diseases, Ninth Revision, Clinical Modification; BAFTA: Birmingham Atrial Fibrillation Treatment of the Aged; CHF: congestive heart failure; CAD: coronary artery disease; DM: diabetes mellitus; MI: myocardial infarction; NABOR: National Anticoagulation Benchmark Outcomes Report; TIA: transient ischemic attack.

\section{Competing interests}

The authors declare that they have no competing interests.

\section{References}

I. Feinberg WM, Blackshear JL, Laupacis A, Kronmal R, Hart RG: Prevalence, age distribution, and gender of patients with atrial fibrillation. Analysis and implications. Arch Intern Med 1995, I55(5):469-473.

2. Miyasaka Y, Barnes ME, Gersh BJ, Cha SS, Bailey KR, Abhayaratna WP, Seward JB, Tsang TS: Secular trends in incidence of atrial fibrillation in Olmsted County, Minnesota, 1980 to 2000, and implications on the projections for future prevalence. Circulation 2006, I I 4(2): I I9-125.

3. Gage BF, Waterman AD, Shannon W, Boechler M, Rich MW, Radford MJ: Validation of clinical classification schemes for predicting 
stroke: results from the National Registry of Atrial Fibrillation. Jama 200I, 285(22):2864-2870.

4. Wolf PA, Abbott RD, Kannel WB: Atrial fibrillation: a major contributor to stroke in the elderly. The Framingham Study. Arch Intern Med 1987, 147(9): I56I-I564.

5. Wolf PA, Abbott RD, Kannel WB: Atrial fibrillation as an independent risk factor for stroke: the Framingham Study. Stroke |99|, 22(8):983-988.

6. Hart RG, Pearce LA, Aguilar MI: Meta-analysis: antithrombotic therapy to prevent stroke in patients who have nonvalvular atrial fibrillation. Ann Intern Med 2007, I 46( I 2):857-867.

7. Darkow T, Vanderplas AM, Lew KH, Kim J, Hauch O: Treatment patterns and real-world effectiveness of warfarin in nonvalvular atrial fibrillation within a managed care system. Curr Med Res Opin 2005, 2I(10):1583-1594.

8. Hylek EM, D'Antonio J, Evans-Molina C, Shea C, Henault LE, Regan S: Translating the results of randomized trials into clinical practice: the challenge of warfarin candidacy among hospitalized elderly patients with atrial fibrillation. Stroke 2006, 37(4): 1075-1080.

9. Waldo AL, Becker RC, Tapson VF, Colgan KJ: Hospitalized patients with atrial fibrillation and a high risk of stroke are not being provided with adequate anticoagulation. J Am Coll Cardiol 2005, 46(9): I729-1736.

10. Go AS, Hylek EM, Phillips KA, Borowsky LH, Henault LE, Chang Y, Selby JV, Singer DE: Implications of stroke risk criteria on the anticoagulation decision in nonvalvular atrial fibrillation: the Anticoagulation and Risk Factors in Atrial Fibrillation (ATRIA) study. Circulation 2000, I02(I): I I-13.

II. Go AS, Hylek EM, Phillips KA, Chang Y, Henault LE, Selby JV, Singer DE: Prevalence of diagnosed atrial fibrillation in adults: national implications for rhythm management and stroke prevention: the AnTicoagulation and Risk Factors in Atrial Fibrillation (ATRIA) Study. Jama 200I, 285( I 8):2370-2375.

12. McCormick D, Gurwitz JH, Goldberg RJ, Becker R, Tate JP, Elwell A, Radford MJ: Prevalence and quality of warfarin use for patients with atrial fibrillation in the long-term care setting. Arch Intern Med 200I, I6I(20):2458-2463.

13. Weisbord SD, Whittle J, Brooks RC: Is warfarin really underused in patients with atrial fibrillation? J Gen Intern Med 200I, I 6(II):743-749.

14. Beyth RJ, Antani MR, Covinsky KE, Miller DG, Chren MM, Quinn LM, Landefeld CS: Why isn't warfarin prescribed to patients with nonrheumatic atrial fibrillation? J Gen Intern Med 1996, I I(I 2):72I-728.

15. Go AS, Hylek EM, Borowsky LH, Phillips KA, Selby JV, Singer DE: Warfarin use among ambulatory patients with nonvalvular atrial fibrillation: the anticoagulation and risk factors in atria fibrillation (ATRIA) study. Ann Intern Med 1999, I 3 I ( I 2):927-934.

16. Fihn SD, Callahan CM, Martin DC, McDonell MB, Henikoff JG, White $\mathrm{RH}$ : The risk for and severity of bleeding complications in elderly patients treated with warfarin. The National Consortium of Anticoagulation Clinics. Ann Intern Med 1996, I 24(I I):970-979.

17. Hart RG, Benavente O, McBride R, Pearce LA: Antithrombotic therapy to prevent stroke in patients with atrial fibrillation: a meta-analysis. Ann Intern Med 1999, I 3 I (7):492-50I.

18. Man-Son-Hing M, Laupacis A: Balancing the risks of stroke and upper gastrointestinal tract bleeding in older patients with atrial fibrillation. Arch Intern Med 2002, I62(5):54I-550.

19. Garcia Rodriguez LA, Hernandez-Diaz S, de Abajo FJ: Association between aspirin and upper gastrointestinal complications: systematic review of epidemiologic studies. $\mathrm{Br} J$ Clin Pharmacol 200I, 52(5):563-57I.

20. Wolfe MM, Lichtenstein DR, Singh G: Gastrointestinal toxicity of nonsteroidal antiinflammatory drugs. N Engl J Med 1999, 340(24): I 888- 1899

21. Piper JM, Ray WA, Daugherty JR, Griffin MR: Corticosteroid use and peptic ulcer disease: role of nonsteroidal anti-inflammatory drugs. Ann Intern Med 199I, I I 4(9):735-740.

22. Gage BF, van Walraven C, Pearce L, Hart RG, Koudstaal PJ, Boode BS, Petersen P: Selecting patients with atrial fibrillation for anticoagulation: stroke risk stratification in patients taking aspirin. Circulation 2004, I I 0(16):2287-2292.
23. Fang MC, Chang Y, Hylek EM, Rosand J, Greenberg SM, Go AS, Singer $D E:$ Advanced age, anticoagulation intensity, and risk for intracranial hemorrhage among patients taking warfarin for atrial fibrillation. Ann Intern Med 2004, I4I (10):745-752.

24. Gage BF, Birman-Deych E, Kerzner R, Radford MJ, Nilasena DS, Rich $M W$ : Incidence of intracranial hemorrhage in patients with atrial fibrillation who are prone to fall. Am J Med 2005, II 8(6):612-6I7.

25. Mant J HR Fitzmaurice $D$ et al: A randomised controlled trial of warfarin versus aspirin for stroke prevention in atrial fibrillation in a primary care population aged over 75. 16th European Stroke Conference 2007.

26. Man-Son-Hing M, Nichol G, Lau A, Laupacis A: Choosing antithrombotic therapy for elderly patients with atrial fibrillation who are at risk for falls. Arch Intern Med 1999, I 59(7):677-685.

27. Fang MC, Go AS, Hylek EM, Chang Y, Henault LE, Jensvold NG, Singer $D E$ : Age and the risk of warfarin-associated hemorrhage: the anticoagulation and risk factors in atrial fibrillation study. $J$ Am Geriatr Soc 2006, 54(8): I23I-I 236.

28. Hylek EM, Evans-Molina C, Shea C, Henault LE, Regan S: Major hemorrhage and tolerability of warfarin in the first year of therapy among elderly patients with atrial fibrillation. Circulation 2007, II 5(2I):2689-2696.

29. Jacobs LG: Warfarin pharmacology, clinical management, and evaluation of hemorrhagic risk for the elderly. Clin Geriatr Med 2006, 22(I): 17-32, vii-viii.
Publish with Bio Med Central and every scientist can read your work free of charge

"BioMed Central will be the most significant development for disseminating the results of biomedical research in our lifetime. "

Sir Paul Nurse, Cancer Research UK

Your research papers will be:

- available free of charge to the entire biomedical community

- peer reviewed and published immediately upon acceptance

- cited in PubMed and archived on PubMed Central

- yours - you keep the copyright
BiolMedcentral 